\title{
The use of oligonucleotide probes to study the ecology of ruminal microbial populations
}

\author{
RI Mackie \\ Department of Animal Sciences and Division of Nutritional Sciences, \\ University of Illinois at Urbana-Champaign, Illinois 61801, USA
}

The microbial community inhabiting the gastrointestinal tract is characterized by its high population density, wide diversity and complexity of interactions. All major groups of microbes are represented in the rumen. Bacteria are predominant but a variety of ciliate protozoa are also present. Anaerobic fungi are widely distributed, becoming more numerous and more obvious in defaunated animals. Yeasts are frequently present and the occurrence of bacteriophage is well documented. These microbial groups are covered in several texts including The Rumen and its Microbes (Hungate, 1966), Microbial Ecology of the Gut (Clarke and Bauchop, 1977) and The Rumen Microbial Ecosystem (Hobson, 1988). The rumen, the most extensively studied gut ecosystem, contains up to $10^{11}$ viable bacterial cells per $\mathrm{ml}$ comprising some 200 or more species, $10^{4}-10^{6}$ ciliate protozoa per $\mathrm{ml}$ distributed over 25 genera, anaerobic rumen fungi divided into four genera with zoospore population densities of $10^{3}-10^{5}$ per $\mathrm{ml}$, and a range of morphological types of bacteriophage with numbers of $10^{7}-10^{9}$ particles per $\mathrm{ml}$ (Clarke, 1977; Klieve and Bauchop, 1988; Orpin and Joblin, 1988; Stewart and Bryant, 1988; Williams and Coleman, 1988; Klieve and Swain, 1993; Hespell et al, 1996).

Despite this vast amount of knowledge, the basic prerequisites for ecological studies, namely enumeration and identification of community members, have tremendous limitations. The two major problems which face rumen microbial ecologists are the inevitable bias introduced by culture based enumeration, isolation and characterization techniques and the lack of a phylogenetically based classification scheme (Ward, 1989; Amann et al, 1990, 1994; Stahl, 1993b). A few examples of these limitations are as follow: total viable counts forming less than $10 \%$ of microscopic counts especially on high forage diets, low viable counts of cellulolytic bacteria and poor recovery of Fibrobacter succinogenes on agar medium, observation of microscopic forms that have never been cultivated (Eadie's ovals, Quinn's ovals), requirement of ciliate protozoa for (rumen) bacteria to provide essential preformed nutrients, morphologically based taxonomy of ciliate protozoa, and wide bacterial species diversity.

Modern molecular ecology techniques based on sequence comparisons of nucleic acids (DNA or RNA) can be used to provide a molecular characterization scheme which predicts natural evolutionary relationships. In principle, nucleic acid probes can be designed to hybridize with a complementary target sequence and thus provide a complete description independent of growth conditions and media used (Amann et al, 1990, 1992a, 1992b; Ward et al, 1992). An example of the power of these modern molecular ecology techniques is provided by the analysis of $16 \mathrm{~S}$ rRNA sequences (average length 1500 nucleotides). The highly conserved regions of the rRNA molecule can serve as primer binding sites for in vitro amplification by PCR (Weisburg et al, 1991; Ludwig et al, 1994). The more conserved regions are also useful, serving as targets for universal probes that react with all living organisms or for discriminating between broad phylogenetic groups such as the domains Archaea, Bacteria and Eucarya. The more variable sequence regions are more appropriate for genus, species and sometimes even strains specific hybridization probes (Stahl and Amann, 1991; Odenyo et al, 1994a, 1994b; Lin and Stahl, 1995). The use of molecular ecology techniques based on nucleic acid hybridization probes is likely to revolutionize our approach to rumen microbial ecology and will provide not simply a refinement or increased 
understanding but a complete description of the system (Stahl, 1988, 1993a; Raskin et al, 1996).

\section{Application of RNA based studies to rumen ecology}

The use of small subunit rRNA methods, referred to 165 rRNA-based methods in gastrointestinal microecology has become well established over the past five years. The principles and practice involved in 165 rRNA methods have been extensively reviewed (Pace et al, 1986; Stahl, 1986, 1993a, 1993b; Stahl and Amann, 1991; Olsen and Woese, 1993). These methods are also applicable to 23S rRNA which will likely be used more extensively in the future since it contains more information (3000 bp compared to $1500 \mathrm{bp}$ for $16 \mathrm{~S}$ rRNA). At present their use is limited because of the less extensive sequence collection available. Extensive comparative sequence analysis of $16 \mathrm{~S}$ rRNA molecules representing a wide diversity of organisms shows that different regions of the molecule vary in sequence conservation. Oligonucleotides complementing regions of universally conserved $16 \mathrm{~S}$ rRNA sequence are used as universal probes while those complementing more variable regions of sequence are useful as selective probes targeting species, genus, or phylogenetic group-specific probes.

The use of 16S rRNA-based methods for ecological studies in the gastrointestinal tract was first demonstrated by Stahl et al (1988). Species specific 16S rRNA targeted oligonucleotide probes were developed to enumerate strains of Fibrobacter (Bacteroides) succinogenes and Lachnospira multiparus in the bovine rumen to monitor shifts in population abundance or changes in population activity in complex microbial communities. Culture based enumeration of $F$. succinogenes was largely unsuccessful in the same study. These techniques formed the basis for further studies of bacterial populations in gut environments. Probes were developed for the other major ruminal cellulolytic bacteria Ruminococcus albus and $R$. flavefaciens and used to study the dynamics of bacterial interactions during fermentation of cellobiose, cellulose and alkaline hydrogen peroxide treated wheat straw (Odenyo et al, 1994a, 1994b). The results showed that $16 \mathrm{~S}$ rRNA targeted oligonucleotide hybridization probes were effective in quantifying specific bacteria in defined mixed cultures and provided useful information on bacterial competition during growth on insoluble substrats. Furthermore, this study revealed for the first time the production of a bacteriocin-like substance by a ruminal bacterium, a mechanism which may be used to compete for nutrients. The ruminal bacterium Synergistes jonesii has attracted considerable interest due to its limited geographical distribution and its ability to degrade 3,4-DHP, the toxic principle of the tropical leguminous shrub Leucaena leucocephala (Allison et al, 1990, 1992). The $16 S$ rRNA sequence of $S$. jonesii was not closely related to any among those bacteria so far characterized and was an ideal candidate to evaluate the use of oligonucleotide probes for tracking bacteria in the ruminal ecosystem. Radiolabeled and fluorescent-dye-conjugated probes were developed for quantitation of $S$. jonesii in a mixed-culture chemostat (McSweeney et al, 1993). Further ecological studies on transmission, colonization, persistence and population studies in vivo are under investigation.

Surprisingly, a limited number of studies have used rRNA based methods to study ruminal protozoa and fungal populations. Finlay et al (1994) used a fluorescently labeled oligonucleotide probe targeting the $16 \mathrm{~S}$ rRNA of the Archaea to demonstrate that Entodinium species and Dasytricha ruminantium contained methanogenic endosymbionts outside digestive vacuoles. Exosymbiotic methanogens had been well documented previously based on characteristic autofluorescence of these bacteria (Stumm et al, 1982). Comparative sequence analysis of the 18S rRNA genes of Neocallimastix was used to phylogenetically position in the Chytridiomycete class of fungi (Doré and Stahl, 1991).

\section{Considerations}

Before application of nucleic acid hybridization techniques, especially those targeting $16 \mathrm{~S}$ rRNA, to rumen microbial ecology, several overlapping concerns are worth considering. For simplicity they are divided into specificity, sensitivity and quantitation although these are not mutually exclusive categories. Although 
critically important to the results obtained, these categories are covered briefly in this paper and gastrointestinal microbial ecologists are referred to authoritative publications on nucleic acid hybridization techniques (Ward, 1989; Sayler and Layton, 1990; Stahl and Amann, 1991; Ward et al, 1992; Raskin et al, 1996).

\section{Specificity}

When rRNA targeted probes are designed in order to quantitate population abundance and activity in natural microbial communities, and in which potential novel organisms reside, probe specificity is an essential consideration. Under appropriate hybridization and wash conditions it is possible to discriminate between targets that differ by a simple nucleotide (Stahl and Amann, 1991). Experimental evaluation of probe specificity needs to be preceded by rRNA database searches for target and nontarget complementarity in order to identify mismatches. Probe design is a dynamic process requiring constant evaluation as more rRNA sequences become rapidly available. The experimental evaluation of probe specificity for the genus, species and strains of Fibrobacter is a thorough illustration of this procedure (Montgomery et al, 1988; Stahl et al, 1988; Amann et al, 1992a).

A second important strategy which can be used to test probe specificity experimentally is the "nesting" of probes. Since different degrees of conservation in rRNA sequences allow for design of general and specific oligonucleotide hybridization probes, a number of probes with increasing levels of specificity (e.g., family-, genus-, and species-specific probes) can be used to characterize a single micro environment. If each set of probes covers the complete diversity of target species present then the sum of amounts of $16 \mathrm{~S}$ rRNAs quantified by a set of probes should equal the amount quantified by a more general probe. However, if the use of the general probe indicates that there is a significant amount of the target present in the sample not accounted for by the combined used of several specific probes then the presence of novel diversity and/or uncultured species and strains is suggested. This approach of probe nesting is well documented in the Fibrobacter studies of Stahl and co-workers (Montgomery et al, 1988; Amann et al, 1992a; Lin and Stahl, 1995).

\section{Sensitivity}

Oligonucleotide hybridization probes targeted towards $16 \mathrm{~S}$ rRNA sequences provide a sensitive means for rapid and accurate measurements of population dynamics in mixed cultures (Stahl et al, 1988; Odenyo et al, 1994a, 1994b). The relatively high copy number of rRNA molecular per cell $\left(10^{3}\right.$ to $\left.10^{5}\right)$ also contributes greatly to the sensitivity of this technique making it possible to detect individual fixed microbial cells with fluorescent end-labeled, rRNA-targeted oligonucleotide probes (DeLong et al, 1989; Amann et al 1990, 1992b; Trebesius et al, 1994; Langendijk et al, 1995). The use of PCR primers specific for $16 \mathrm{~S}$ rRNA gene sequences followed by hybridization detection of specific PCR products enhances both specificity and sensitivity. This technique when applied to the analysis of Bacteroides was very sensitive allowing detection of $10^{-13} \mathrm{~g}$ of target DNA or as few as one to five bacterial cells (Kreader, 1995).

\section{Quantitation}

Abundance of a phylogenetically-defined microbial population in a sample is determined by comparison of hybridization signal intensities from dilution series of reference RNA applied to the same membrane. The results are usually expressed as ng group specific RNA per $g$ of extracted sample or as a percentage of the total 16S rRNA in the sample (Stahl and Amann, 1991). It is also possible to normalize concentrations of RNA samples with reference to a standard reference series of $E$. coli $16 \mathrm{~S}$ rRNA and therefore quantitates relative abundance (McSweeney et al, 1993; Odenyo et al, 1994a, 1994b). Accurate characterization of microbial communities using membrane hybridization is also dependent on an unbiased recovery of nucleic acids from entire sample. Differential extraction and recovery of nucleic acid can result in immediate bias and needs to be considered in detail (Ward, 1989; Stahl and Amann, 1991; Raskin et al, 1996). The relationship between concentration of target 16S rRNA in the extract and the measured hybridization response is also critical in providing accurate population assessments (Ward, 1989; Stahl and Amann, 1991; Raskin et al, 1996). 


\section{Future directions}

New molecular technologies, both DNA and RNA based are beginning to improve our knowledge and understanding of rumen microbial ecology. Although the use of this technology is not widespread, it is likely to revolutionize our approach and provide for the first time a complete description of the ruminal ecosystem. Rather than replacing the classical culture based system, the new molecular techniques can be used in combination with the classical in order to improve cultivation, speciation and evaluation of biodiversity. It is worth noting that the comparative sequence database is largely the result of pure culture studies. It is also worth considering what $16 \mathrm{~S}$ rRNA abundance measures. It may not directly relate to organism abundance since the copy number per cell varies considerably and can also be detected in dormant or inactive community members. These methods may provide quantitative measures of the active members of a microbial community thus providing a hybrid population-activity probe. Finally, the combined application of population and activity (gene) probes will enable rumen ecologists to determine the most difficult question in microbial ecology, the exact role or function a specific organism plays in the natural environment and its quantitative contribution to the whole.

\section{Literature cited}

Allison MJ, Hammond AC, Jones RJ (1990) Detection of ruminal bacterial that degrade toxic dihydropyridine compounds produced from mimosine. App/ Environ Microbiol 56, 590-595

Allison MJ, Mayberry WR, McSweeney CS, Stahl DA (1992) Synergistes jonesii, gen. nov., sp. nov.: a rumen bacterium that degrades toxic pyridinediols. Syst App/ Microbiol 15, 522-529

Amann RI, Krumholtz L, Stahl DA (1990) Fluorescentoligonucleotide probing of whole cells for determinative, phylogenetic, and environmental studies in microbiology. J Bacteriol 172, 762-770

Amann Rl, Ludwig W, Schleifer KH (1994) Identification of uncultured bacteria a challenging task for molecular taxonomists. ASM News 60 , 360-365

Amann RI, Lin C, Key R, Montgomery L, Stahl DA (1992a) Diversity among Fibrobacter isolates: towards a phylogenetic classification. Syst Appl Microbiol 15, 23-31

Amann RI, Zarda B, Stahl DA, Schleifer KH (1992b) Identification of individual prokaryotic cells with enzyme-labeled, rRNA-targeted oligonucleotide probes. App/ Environ Microbiol 58, 3007-3011

Clarke RTJ (1977) The gut and its micro-organisms. In: Microbial ecology of the gut (Clarke RTJ, Bauchop T, eds) Academic Press, New York, 3571

Clarke RTJ, Bauchop T (1977) Microbial ecology of the gut. Academic Press, New York, $410 p$

DeLong EF, Wickham GS, Pace NR (1989) Phylogenetic strains: ribosomal RNA-based probes for the identification of single cells. Science 243, 1360-1363

Doré J, Stahl DA (1991) Phylogeny of anaerobic rumen Chytridiomycete inferred from small subunit ribosomal RNA sequence comparisons. Can J Bot 69, 1964-1971

Finlay BJ, Esteban G, Clarke KJ, Williams AG, Embly TM, Hirt RP (1994) Some rumen ciliates have endosymbiotic methanogens. FEMS Microbiol Lett 117, 157-162

Hespell RB, Dehority BA, Akin DE (1996) The bacteria, protozoa, and fungi of the rumen. $/ n$ : Ecology and physiology of gastrointestinal microbes (Mackie RI, White BA, Isaacson RE, eds) Chapman and Hall, New York,

Hobson PN (1988). The rumen microbial ecosystem. Elsevier Appi Sci, New York, $527 \mathrm{p}$

Hungate RE (1966) The rumen and its microbes. Academic Press, New York, $533 \mathrm{p}$

Klieve A, Bauchop T (1988) Morphological diversity of ruminal bacteriophages from sheep and cattle. Appl Environ Microbiol 54, 1637-1641

Klieve A, Swain RA (1993) Estimation of ruminal bacteriophage numbers by pulsed-field gel electrophoresis and laser densitometry. Appl Environ Microbiol 59, 2299-2303

Kreader CA (1995) Design and evaluation of Bacteroides DNA probes for the specific detection of human fecal pollution. Appl Environ Microbio/61, 1171-1179

Langendijk $P$, Schut $F$, Jansen GJ, Raangs GC, Camphuis GR, Wilkinson MF, Welling GW (1995) Quantitative fluorescence in situ hybridization of Bifidobacterium spp. with genus-specific $16 \mathrm{~S}$ rRNA-targeted probes and its application in fecal samples. App/ Environ Microbiol 61, 3069-3075

Lin C, Stahl DA (1995) Taxon-specific probes for the cellulolytic genus Fibrobacter reveal abundant and novel equine-associated populations. Appl Environ Microbiol 61, 1348-1351

Ludwig W, Dorn S, Springer N, Kirchhof G, Schleifer $\mathrm{KH}$ (1994) PCR-based preparation of 23S rRNA- 
targeted group-specific polynucleotide probes. Appl Environ Microbiol 60, 3236-3244

McSweeney CS, Mackie RI, Odenyo AA, Stahl DA (1993) Development of an oligonucleotide probe and its application for detection and quantitation of the ruminal bacterium Synergistes jonesii in a mixed-population chemostat. App/ Environ Microbiol 59, 1607-1612

Montgomery L, Flesher B, Stahl DA (1988) Transfer of Bacteroides succinogenes (Hungate) to Fibrobacter gen. nov. as Fibrobacter succinogenes comb. nov. and description of Fibrobacter intestinalis $\mathrm{sp}$. nov. Int $J$ Syst Bacteriol 38, 430-435

Odenyo AA, Mackie RI, Stahl DA, White BA (1994a) The use of 16S rRNA-targeted oligonucleotide probes for Ruminococcus species and evidence for bacteriocin production. Appl Environ Microbiol $60,3688-3696$.

Odenyo AA, Mackie RI, Stahl DA, White BA (1994b) The use of $16 \mathrm{~S}$ rRNA-targeted oligonucleotide probes to study competition between ruminal fibrolytic bacteria: pure culture-studies with cellulose and alkaline peroxide-treated wheat straw. Appl Environ Microbiol 60, 3697-3703

Olsen GJ, Woese CR (1993) Ribosomal RNA, a key to phylogeny. FASEB J 7, 113-123

Orpin CG, Joblin KN (1988) The rumen anaerobic fungi. In: The rumen microbial ecosystem (Hobson PN, ed) Elsevier Appl Sci, New York, 129-150

Pace NR, Stahl DA, Lane DJ, Olsen GJ (1985) Analyzing natural microbial populations by rRNA sequences. ASM News 51, 4-12

Raskin L, Capman WC, Sharp R, Stahl DA (1996) Molecular ecology of gastrointestinal ecosystems. In: Ecology and physiology of gastrointestinal microbes (Mackie RI, White BA, Isaacson RE, eds) Chapman and Hall, New York

Sayler GS, Layton AC (1990) Environmental application of nucleic acid hybridization. Ann Rev Microbiol 44, 625-648

Stahl DA (1986) Evolution, ecology, and diagnostics: unity in variety. Bio/ Technology 4, 623-628

Staht DA (1988) Phylogenetically based studies of microbial ecosystem perturbation. In:
Biotechnology for crop protection (Hedin P, Menn $\mathrm{JJ}$, Hollingsworth RM, eds) American Chemical Society symposium volume, American Chemical Society, Washington DC, 373-390

Stahl DA (1993a) The natural history of microorganisms. ASM News 59, 609-613

Stahl DA (1993b) Comparison of nucleic acids from microorganisms: sequencing approaches. Molecular evolution: producing the biochemical data. Methods Enzymol 224, 373-391

Stahl DA, Amann R (1991) Development and application of nucleic acid probes. In: Nucleic acid techniques in bacterial systematics (Stackebrandt E, Goodfellow M, eds) John Wiley and Sons, Chichester, England, 205-248

Stah| DA, Flesher B, Mansfield HR, Montgomery L (1988) Use of phylogenetically based hybridization probes for studies of ruminal microbial ecology. App/ Environ Microbiol 54, 1079-1084

Stewart CS, Bryant MP (1988) The rumen bacteria. In: The rumen microbial ecosystem (Hobson PN, ed) Elsevier Appl Sci, New York, 21-76

Stumm CK, Gigzen HJ, Vogels GD (1982). Association of methanogenic bacteria with ovine rumen ciliates. $\mathrm{Br} J$ Nutr 47, 95-99

Trebesius KH, Amann R, Ludwig W, Mühlegger K, Schleifer KH (1994) Identification of whole fixed bacterial cells with non-radioactive 235 rRNAtargeted polynucleotide probes. App/ Environ Microbiol 60, 3228-3225

Ward DM (1989) Molecular probes for analysis of microbial communities. In: Structure and function of biofilms (Characklis WG, Wilderer PA, eds) John Wiley and Sons Inc, New York, 145-163

Ward DM, Bateson MM, Weller R, Ruff-Roberts AL (1992) Ribosomal RNA analysis of microorganisms as they occur in nature. $A d v$ Microbiol Ecol 12, 219-286

Weisburg WG, Barns SM, Pelletier DA, Lane DJ (1991) 165 ribosomal DNA amplification for phylogenetic study. J Bacteriol 173, 697-703

Williams AG, Coleman GS (1988) The rumen protozoa. In: The rumen microbial ecosystem (Hobson PN, ed) Elsevier Appl Sci, New York, 77-128 